\title{
STUDI ANALISIS TENTANG RESILIENSI TERKAIT HARGA DIRI DAN SOSIAL KOGNITIF PADA REMAJA PANTI ASUHAN ANAK HARAPAN SAMARINDA
}

\author{
Analytical Study on Resilience of Self-Esteem and Social Cognitive of Adolescents At Panti \\ Asuhan Anak Harapan Samarinda
}

\author{
Rusni Masnina \\ Dosen Prodi Ilmu Keperawatan Fakultas Ilmu Kesehatan UMKT
}

\begin{abstract}
ABSTRAK
Latar Belakang : Masa Remaja adalah periode kehidupan seorang anak yang berkembang menjadi dewasa. Masa remaja sering ditandai dengan transisi dan perubahan. Menghadapi kehidupannya dimasa depan. Remaja perlu memiliki keyakinan dan harapan yang besar agar mampu bangkit dari kondisi sulit dan pengalaman emosional negatif yang dialaminya. Bagi remaja yang tinggal dipanti asuhan, tidak memiliki keluarga ataupun yang tinggal tidak bersama orang tua tentu perlu membentuk kepribadian yang kuat dalam hal harga diri, sosial kognitif dan resliensi diri untuk menjadi manusia dewasa yang berguna dan bertanggung jawab baik atas diri sendiri maupun bagi masyarakat di kemudian hari.

Tujuan Penelitian : Penelitian ini bertujuan untuk menganalisis "Resiliensi terkait Harga Diri dan Sosial Kognitif pada Remaja Panti Asuhan Anak Harapan Samarinda"

Rancangan Penelitian : Rancangan penelitian ini adalah deskriptif cross sectional. Populasi dalam penelitian ini adalah remaja panti berjumlah 90 orang dengan sampel 73 responden yang diambil mengunakan metode purposive sampling, dimana penelitian ini mengunakan kriteria inklusi dan eksklusi. Analisis yang digunakan dalam penelitian adalah uji statistic chi-square

Hasil Penelitian : Berdasarkan hasil penelitian didapatkan ada hubungan yang signifikan antara harga diri dengan resiliensi pada remaja panti ( $\mathrm{p}$ value $=0,016<\alpha=0,05$ ), demkian pula hasil analisis antara sosial kognitif dengan resiliensi pada remaja panti asuhan anak harapan samarinda ditemukan ada hubungan yang signifikan ( $\mathrm{p}$ value $: 0.000<\alpha 0.05$ )

Kesimpulan : peneliti merumuskan responden yang memiliki resiliensi mayoritas lebih baik dikarenakan harga diri dan sosial kognitif pada remaja panti asuhan harapan samarinda selain dipengaruhi faktor dari dalam diri juga mendapat dukungan dari orang-orang sekitar khususnya pengasuh di panti asuhan anak harapan Samarinda.
\end{abstract}

\section{Kata Kunci : Resiliensi, Harga diri, Sosial Kognitif}

\section{ABSTRACT}

Background: Adolescence is the period of life of a child who develops into adulthood. Adolescence is often characterized by transitions and changes. Facing his life in the future, adolescents need to have great confidence and hope in order to be able to rise from the difficult conditions and negative emotional experience experienced. For adolescents who live in the orphanage, not having a family or not living with their parents necessarily need to form a strong personality in terms of self-esteem, social cognitive and self-resilience to become adult human beings who are useful and responsible both for themselves and for the people in later.

Objectives: This study was aimed to analyze "Resilience related to Self-Esteem and Social Cognitive among adolescents at Panti Asuhan Anak Harapan Samarinda"

Methods: The design of this study was descriptive cross-sectional. Population in this research was adolescent amounted to 90 people with the sample of 73 respondents taken using purposive sampling method, where this research use inclusion and exclusion criteria. The statistical analysis used in this research was chi-square statistic test

Results: Based on the results of the study, there was a significant relationship between self-esteem and resilience in adolescent ( $p$ value $=0,016<\alpha=0,05$ ), as well as there was significant relationship between social cognitive and resilience ( $p$ value: $0.000<\alpha 0.05$ ) 
Conclusion: Majority of adolescent who have better resilience was due to better self-esteem and social cognitive. Beside influenced by these inner factors they were also supported from people around especially the caregivers at the orphanage.

Keywords: Resilience, Self-esteem, Social Cognitive

\section{PENDAHULUAN}

Remaja sebagai generasi muda perlu dibentuk memilki kepribadian yang kuat guna produktivitas kerja yang optimal dalam membangun bangsa dan Negara. Menghadapi kehidupannya dimasa depan remaja perlu memiliki keyakinan dan harapan yang besar agar mampu bangkit dari kondisi sulit dan pengalaman emosional negatif yang dialaminya

Menurut Coleman \& Hendry (1999 dalam Henningsen, 2011) masa remaja adalah periode kehidupan seorang anak yang berkembang menjadi dewasa. Masa remaja sering di tandai dengan transisi dan perubahan.

Bagi remaja yang tinggal dipanti asuhan, tidak memiliki keluarga ataupun yang tinggal tidak bersama orang tua tentu perlu membentuk kepribadian yang kuat. Panti Asuhan merupakan lembaga yang bergerak dibidang sosial untuk membantu anak-anak yang tidak memiliki orang tua. Resiliensi atau kekuatan untuk bangkit dari suatu keterpurukan penting untuk dimiliki oleh setiap individu.

Penelitian di Indonesia oleh organisasi kemanusiaan Save the Children bekerja sama dengan United Nations Children's Fund (UNICEF) pada akhir tahun 2009, menemukan sekitar 6\% dari lima ratus ribu anak berada dalam pengasuhan rumah yatim piatu adalah anak yang benar-benar yatim piatu, 94\% menjadi penghuni panti karena alasan kemiskinan, orang tua tidak mampu untuk menafkahi dengan layak sehingga anak-anak mereka dititipkan di rumah pengasuhan yatim piatu (Yuniana, 2012). Berdasarkan hasil penelitian mengenai data yatim piatu, banyak sebab yang mendasari para remaja dan anak-anak berada di panti asuhan. Beberapa di antaranya ada yang memang kelahirannya tidak dikehendaki oleh orang tua mereka sehingga mereka dititipkan di panti asuhan, ada yang karena keterbatasan ekonomi sehingga tidak bisa membiayai mereka, ada juga yang memang kehilangan orang tua mereka sejak kecil

Panti asuhan adalah wadah bagi anak- anak yang kehilangan keluarganya, maka dari itu pentingnya untuk saling berinteraksi sesama penghuni panti, perlunya resiliensi untuk mengatasi kesulitan agar tidak terjadi permasalahan dan pelanggaran yang dilakukan dipanti asuhan. Newcom dalam Laframboise dkk, (2006) melihat resiliensi sebagai suatu mekanisme perlindungan yang memodifikasi respon individu terhadap situasi-situasi yang beresiko pada titik-titk kritis sepanjang kehidupan seseorang

Remaja yang memiliki resiliensi baik dapat dilihat melalui kemampuannya untuk meregulasi emosi, mengendalikan impuls-impuls negatif yang muncul, seorang individu yang optimis, mampu berempati, memiliki harapan dan keyakinan yang kuat untuk bangkit, memiliki efikasi diri yang baik, serta aspek-aspek positif dalam hidupnya meningkat. Hal ini juga didukung oleh faktor-faktor dari dalam diri dan dari luar diri individu yang mempengaruhi individu untuk menjadi seorang yang resilien. Faktor-faktor dari luar diri individu antara lain hubungan sosial yang baik antara individu dengan orangtua dan lingkungan sekitarnya, mendapatkan dukungan yang positif dari orang-orang disekitarnya, sedangkan faktor dari dalam diri individu yaitu memiliki perasaan dicintai dan mampu untuk mencintai orang lain, menjalin hubungan baru, dan mampu berempati. Remaja juga memiliki keyakinan dan harapan yang besar akan kehidupannya di masa yang akan datang, sehingga mampu bangkit dari kondisi sulit dan pengalaman emosional negatif yang dialaminya (Swastika, 2010).

Panti Sosial Asuhan Anak Harapan Samarinda menampung sejumlah 100 anak. Anak yang berusia 6-11 tahun sebanyak 9 orang dan 1 orang yang berusia 23 tahun. Anak yang berusia 12 sampai dengan 22 sebanyak 90 orang. Jadi jumlah anak remaja dipanti total 90 orang. Dari 15 remaja yang di wawancarai, 8 orang yang memiliki kemampuan kognitif baik yaitu bisa melakukan sesuatu dengan baik, membaca situasi, respon dan pemahaman dan resiliensi yang baik. Ada 2 orang yang memiliki kemampuan kognitif dan resiliensi yang buruk yaitu masalah dalam mengatasi 
emosi. Memiliki perasaan bersalah, stres, dan cemas dan masalah tingkah laku. 3 orang remaja mampu mengontrol emosi, tidak mudah tersinggung, percaya diri, dan dapat menerima kritikan dari orang lain, disiplin ketika melakukan aktifitas di panti asuhan. Sedangkan 2 orang lainnya tidak percaya diri malu bila bertemu orang asing, mudah tersinggung dan tidak mempedulikan lingkungan yang di tempati saat ini.

\section{TUJUAN PENELITIAN}

Tujuan umum dalam penelitian untuk mengetahui "Resiliensi terkait Harga Diri dan Sosial Kognitif pada Remaja Panti Asuhan Anak Harapan Samarinda". Adapun tujuan khusus ada 2 yaitu:

1. Menganalisis hubungan antara Harga diri dengan Resiliensi pada Remaja Panti Asuhan Anak Harapan Samarinda

2. Menganalisis hubungan antara sosial kognitif dengan Resiliensi pada Remaja Panti Asuhan Anak Harapan Samarinda

\section{METODE PENELITIAN}

Rancangan penelitian ini adalah deskriptif yaitu penelitian yang bertujuan untuk mengungkapkan gambaran variabel independent (Nursalam, 2011), dengan metode pendekatan cross sectional yaitu penelitian untuk mempelajari dinamika observasi atau pengumpulan data sekaligus pada satu saat (point approach) (Notoatmodjo, 2010).

Tehnik sampling pada penelitian ini menggunakan purposive sampling pada responden remaja panti yang berusia remaja (12-22 tahun) sejumlah 90 orang. Berdasarkan rumus besar sampel untuk penelitian survey dengan populasi (N) yang diketahui menurut Lemeshow, et al. (1997) sebagai berikut:

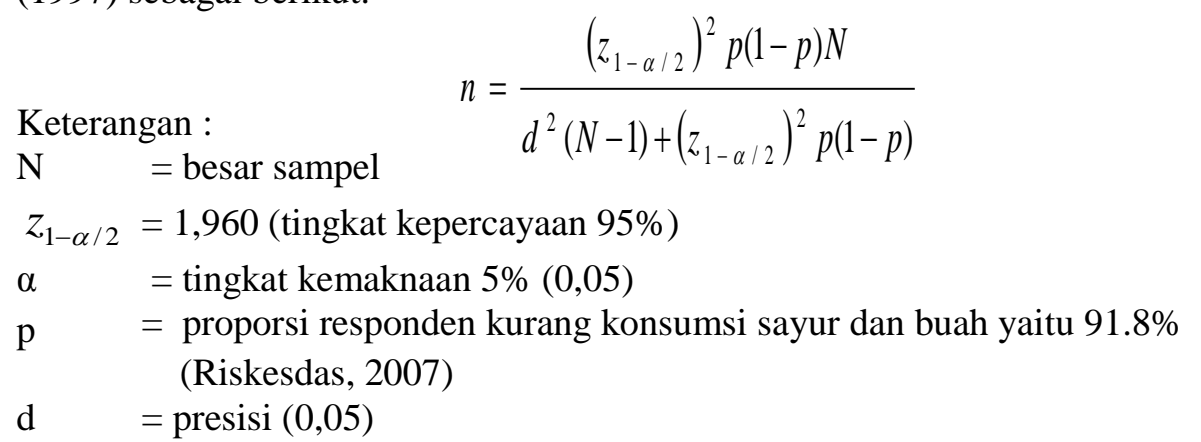

Berdasarkan perhitungan rumus diatas diperoleh jumlah sampel yang dibulatkan (n) sebesar 73 responden. Peneliti juga menentukan kriteria sampel untuk membantu mengurangi terjadinya bias pada hasil penelitian. Adapun kriteria sampel penelitian ini adalah sebagai berikut :

a. Kriteria inklusi, yaitu :

1) Remaja yang berusia 12- 22 tahun.

2) Remaja yang tingal di Panti Sosial Anak Harapan Samarinda.

3) Bersedia menjadi responden.

b. Kriteria Eksklusi, yaitu:

1) Remaja yang mengalami ganguan mental

2) Remaja yang terbukti mengunakan narkoba/obat-obatan terlarang.

3) Remaja yang tidak bersedia menjadi responden.

\section{HASIL PENELITIAN}

\section{A. Karakteristik responden}

Tabel 1. Distribusi Karakteristik responden Remaja Patni Sosial Anak Harapan Samarinda

\begin{tabular}{cccc}
\hline & Katagori & frekuensi & Presentase(\%) \\
\hline \multirow{2}{*}{ Jenis kelamin } & Laki-laki & 34 & 46,6 \\
\cline { 2 - 4 } & Perempuan & 39 & 53,4 \\
\hline Total & & 73 & 100,0 \\
\hline
\end{tabular}




\begin{tabular}{cccc}
\hline pendidikan & & & \\
\hline & SD & 16 & 21,9 \\
\cline { 2 - 4 } & SMP & 32 & 43,8 \\
\cline { 2 - 4 } & SMA & 25 & 34,2 \\
\hline Total & & 73 & 100,0 \\
\hline Usia & & & \\
\hline & $>20$ & 16 & 21,9 \\
\cline { 2 - 4 } & $<20$ & 57 & 78,1 \\
\hline Total & & 73 & 100,0 \\
\hline
\end{tabular}

Sumber: Data Primer 2017

\section{B. Uji Analisis}

\section{Harga diri dengan Resiliensi}

Analisa bivariat untuk mengetahui ada atau tidaknya Hubungan antara Harga Diri dengan Resiliensi pada remaja Panti Sosial Anak Harapan Samarinda didapatkan hasil pada tabel yang disajikan berikut;

Tabel 2. Hubungan antara Harga Diri dengan Resiliensi pada Remaja Panti Sosial Anak Harapan Samarinda

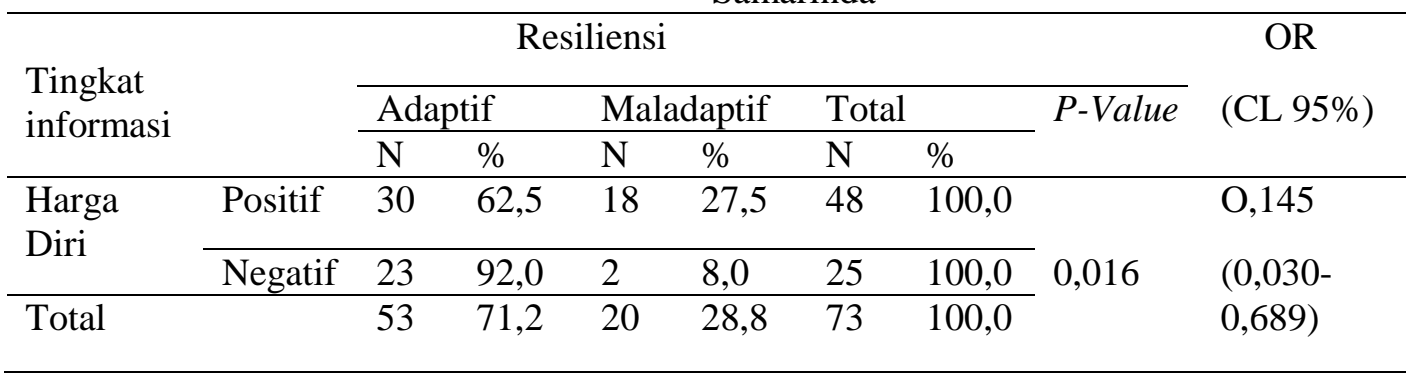

Sumber : Data Primer 2017

\section{Sosial Kognitif dengan Resiliensi}

Analisis bivariat untuk mengetahui ada atau tidaknya hubungan antara Sosial Kognitif dengan Resiliensi pada Remaja Panti Sosial Anak Harapan Samarinda didapatkan hasil seperti yang terlihat pada tabel yang disajikan berikut:

Tabel 3. Hubungan Antara Sosial Kognitif dengan Resiliensi Pada Remaja Panti Sosial Asuhan Anak Harapan Samarinda

\begin{tabular}{|c|c|c|c|c|c|}
\hline \multirow{3}{*}{$\begin{array}{c}\text { Sosial } \\
\text { kognitif }\end{array}$} & \multicolumn{2}{|c|}{ Resiliensi } & \multirow[b]{3}{*}{ Total } & \multirow{3}{*}{$\begin{array}{c}\mathrm{p} \\
\text { Value }\end{array}$} & \multirow{3}{*}{$\begin{array}{c}\text { OR } \\
(\mathrm{CI} 95 \%)\end{array}$} \\
\hline & Baik & ang Baik & & & \\
\hline & & & & & \\
\hline Tinggi & $34(46,6 \%)$ & $6(8,2)$ & $40(54,8)$ & \multirow[t]{2}{*}{0,000} & \multirow{2}{*}{$\begin{array}{c}56,667 \\
\text { (CI 95\%: } 13,025- \\
2,46,529)\end{array}$} \\
\hline Rendah & $3(4,1 \%)$ & $30(41,1)$ & $33(45,2)$ & & \\
\hline Total & $37(50,7 \%)$ & $36(49,3)$ & 73(100) & & \\
\hline
\end{tabular}

Sumber : Data Primer 2017

\section{Pembahasan}

\section{Harga diri dengan Resiliensi}

Hasil penelitian didapatkan dari 73 responden berdasarkan tabel 2. di atas menunjukkan bahwa $\rho$-value yaitu 0,016 yang lebih kecil dari nilai alpha 0,05 yang berarti hipotesa nol (Ho) di tolak sehingga dapat disimpulkan bahwa terdapat hubungan yang bermakna antara Harga Diri dengan Resiliensi pada remaja Panti Asuhan Anak Harapan Samarinda. 
Dari hasil analisa di atas diperoleh pula nilai odds ratio $(\mathrm{OR})=0,145$ (95\% CI 0,0300,689 ) artinya remaja panti yang memiliki harga diri positif berpeluang sebanyak 0,145 kali untuk mampu beradaptasi dibandingkan dengan remaja panti yang memiliki harga diri negatif. Hasil tersebut diyakini dengan tingkat kepercayaan 95\% peluang remaja panti yang memiliki harga diri positif dapat dapat mempunyai resiliensi adaptif dibandingkan dengan remaja panti yang memiliki resiliensi maladaptif.

Begitu pula hasil penelitian yang dilakukan oleh Widodo dan Pratitis (2013) dengan judul Harga Diri dan Interaksi Sosial pada Remaja Panti Asuhan, yang tinggal bersama keluarga di Kabupaten Purbalingga. hasil uji hipotesis didapatkan angka koefisien korelasi sebesar 0,656 dengan $\mathrm{p}=0,000(\mathrm{p}<0,05)$. Koefisien korelasi tersebut menunjukkan bahwa adanya Hubungan yang positif antara Harga Diri dan Interaksi Sosial pada remaja panti asuhan dan remaja yang tinggal bersama keluarga di Kabupaten Purbalingga.

Menurut Lubis (2009) harga diri adalah pandangan individu terhadap nilai dirinya atau bagaimana seseorang menilai, mengakui, menghargai, atau menyukai dirinya sendiri. Santrock dalam Amrullah (2013), Lingkungan yang membuat remaja merasa diterima, dihargai dan di hormati. Akan menjadikan remaja merasa bahwa dirinya bernilai untuk dirinya sendiri dan orang lain.

Resiliensi adalah kemampuan atau kapasitas insani yang dimiliki seseorang, kelompok, atau individu masyarakat yang memungkinkannya beradaptasi, mencegah, meminimalkan dan bahkan menghilangkan dampak-dampak yang merugikan dari kondisi-kondisi yang tidak menyenangkan atau bahkan mengubah kondisi kehidupan yang menyengsarakan menjadi suatu yang wajar untuk diatasi (Deswita,2013). Faktor individu meliputi kemampuan kognitif individu, konsep diri, harga diri dan kompetensi sosial yang memiliki individu. Keterampilan kognitif berpengaruh penting pada resiliensi individu. Intelejensi minimal rata-rata dibutuhkan bagi pertumbuhan resiliensi pada diri individu karena resiliensi sangat terkait erat dengan kemampuan untuk memahami dan menyampaikan sesuatu lewat bahasa yang tepat, kemampuan membaca, dan komunikasi non verbal. Resiliensi juga dihubungkan kemampuan untuk melepaskan fikiran dari trauma dengan menggunakan fantasi dan harapan-harapan yang ditumbuhkan pada diri individu yang bersangkutan (Robin, 2006).

Berdasarkan analisis peneliti beransumsi bahwa harga diri berpengaruh bagi remaja di panti asuhan, harga diri yang bersumber dari cara pola asuh penganti orang tua yaitu menghargai kelebihan, menghargai potensi diri, dan menerima kekurangan diri sendiri, dapat merubah prilaku remaja dalam menilai sesuatu dengan positif, serta resiliensi mempunyai kaitan dengan penilaian diri remaja yang adaptif dapat beradaptasi dengan lingkungan yang mengancam ketika berada di panti asuhan, sedangkan harga diri yang negatif terhadap diri sendiri adalah penilaian tidak suka atau tidak puas terhadap kekuranga diri sendiri dan tidak menghargai kelebihan diri dengan melihat diri sebagai sesuatu yang selalu kurang. Serta diharapkan remaja panti dapat mempertahankan prilaku harga diri positif yang baik agar lebih percaya diri dalam melakukan kegiatan dan resiliensi yang adaptif untuk dapat beradaptasi didalam panti maupun diluar panti agar bisa diterima oleh lingkungan sekitar panti.

\section{Sosial Kognitif dengan Resiliensi}

Hasil penelitian didapatkan dari 73 responden pada table 3 didapatkan bahwa $p$ value $=0,000$ lebih kecil dari $\alpha=0,05$ serta dengan nilai OR 56,667 artinya Ho ditolak sehingga dapat disimpulkan ada hubungan antara sosial kognitif dengan resiliensi pada remaja Panti Sosial Asuhan Anak Harapan Samarinda. Hal ini sejalan dengan penelitian yang dilakukan oleh Mulia (2014) dengan judul "hubungan dukungan sosial terhadap teman sebaya tingkat resiliensi remaja di panti asuhan". Penelitian ini mengunakan uji Chi-square didapatkan hasil $p$ - value sebesar 0,015 yang berarti lebih kecil $p$-value $\alpha<(0,05)$ maka dapat disimpulkan terdapat hubungan bermakna antara hubungan dukungan sosial terhadap teman sebaya tingkat resiliensi remaja panti asuhan. Penelitian lain juga dilakukan Hartati (2012) yang berjudul "hubungan pendekatan kognitif dengan kecendrungan prilaku 
deliquensi pada remaja". Penelitian ini menggunakan uji Chi-square didapatkan hasil $p$ value sebesar 0,005 yang berarti lebih kecil $p$-value $\alpha<(0,05)$ maka dapat di simpulkan ada hubungan bermakna antara pendekatan kognitif dengan kecenderungan prilaku deliguensi pada remaja.

Hasil penelitian Hefter (2009) menunjukkan bahwa remaja yang berada di ruang lingkup lingkungan panti memiliki perbedaan yang signifikan dalam berprilaku, memilki tingkat adaptasi yang baik dan mental yang kuat dalam menghadapi permasalahan yang muncul. Menurut Conor (2006) proses individu dalam pembelajaran, dalam menjalani tantangan kehidupan membuat cara berfikir individu menjadi berkembang, dapat mengatasi masalah mampu beradaptasi dengan baik memiliki resiliensi yang bagus. Menurut Cristine (2006) mengatakan bahwa keterampilan interpersonal, kompetensi, serta spiritualitas mencakup kemampuan kognitf yang mempengaruhi kemampuan seseorang untuk berfikir secara logis yang mampu menunbuhkan pikiran pada individu untuk meningkatkan kemampuan resiliensi pada anak tersebut.

Sejalan dengan teori Robin (2006) faktor individual meliputi kemampuan kognitif dan kompetensi sosial yang dimiliki individu. Keterampilan kognitif berpengaruh pada resiliensi individu. Intelegensi minimal rata-rata di butuh kan bagi pertumbuhan resiliensi pada individu karena resiliensi sangat terkait erat dengan kemampuan untuk memahami dan menyampaikan sesuatu lewat bahasa yang tepat. Resiliensi dihubungkan dengan kemampuan untuk melepaskan pikiran dari trauma dengan menggunakan fantasi dan harapan- harapan yang di tumbuhkan pada diri individu.

Berdasarkan analisis diatas peneliti berasumsi kognitif begitu berpengaruh bagi remaja panti, kognitif yang bersumber dari cara berfikir, dapat mengubah perilaku remaja menjadi lebih baik dalam dalam menentukan pilihan, melakukan tindakan yang tidak merugikan remaja itu sendiri. Sementara resieliensi memiliki kaitan terhadap pola pikir remaja yang baik dapat menempatkan diri lingkungan untuk dapat menyesuaikan dengan situasi-situasi yang mengancam saat berada di panti. kognitif yang rendah menjadi penghalang untuk remaja berkembang dalam berbagai aspek pebelajaran menyebabkan tidak dapat beradapatasi dengan baik memiliki kesulitan untuk menentukan pilihan adaptasi sesama teman sebaya dan tidak dapat menyelesaikan permasalahan yang ada. Kemudian dapat diharapakan dari remaja panti dapat mempertahankan proses kognitif dan lebih berkembang agar memilki pola pikir yang lebih matang serta resiliensi yang baik untuk dapat beradaptasi, berguna serta diterima di panti maupun di luar panti.

\section{KESIMPULAN}

Berdasarkan hasil penelitian mengenai Resiliensi terkait Harga Diri dan Sosial Kognitif pada Remaja Panti Asuhan Anak Harapan Samarinda didapatkan kesimpulan bahwa :

A. Ada hubungan yang bermakna antara Harga Diri dengan Resiliensi pada remaja Panti Asuhan Anak Harapan Samarinda dimana $\rho$-value yaitu 0,016 yang lebih kecil dari nilai alpha 0,05 yang berarti hipotesa nol (Ho) di tolak

B. Ada hubungan yang bermakna antara Sosial Kognitif dengan Resiliensi pada remaja Panti Sosial Asuhan Anak Harapan Samarinda ( $p$ value $=0,000$ lebih kecil dari $\alpha=0,05$ ) artinya Ho ditolak

\section{DAFTAR PUSTAKA}

Conor. (2006). Prediting Health Behaviour. Englad. Open University Press.

Cristine. (2006). Strategi dan Teknik Mengajar Dengan Berkesan. Bandung: Pt Setia Purna Inves.

Deswita. (2006). Psikologi Perkembangan. Bandung. Remaja Rosdakarya.

Hefter, M. (2009). Pengembangan Pemebelajaran Dan Pendidikan Remaja. Jakarta: Salemba Medika.

Hartati. (2012). Hubungan Pendekatan Kognitif dengan Kecendrungan Prilaku Deliquensi Pada Remaja. 
Henningsen, M. (2011) Sosiodemographic, Phisical Activity and Self Esteem correlates of Dietary Habits Among Adolescent in Trondheim, Norway. Research Article. Departement of Social Work and Health Science, Norwegian: University of Science and Tehnology, NTNU

La framboise, Teressa. D. (2006). Familiy, Commniy, and School Influences On Resilience Among American Indian Adolescent In The Upper Midwest. Journal of Social Psyhology

Lemeshow, S., Hosmer, D.W., Klar. J., Lwanga, S.K. (1997) Besar Sampel dalam Penelitian Kesehatan. Yogyakarta: Gadjah Mada Unversity Press

Nursalam. (2011). Konsep Dan Penerapan Metodologi Penelitian Ilmu Keperawatan. Jakarta: Salemba Medika.

Notoatmodjo, S. (2010). Metodologi Penelitian Kesehatan. Rinerka Cipta : Jakarta

Piaget. (2008). Teori Perkembangan Kognitif.Jakarta: Salemba Humanika.

Swastika.(2010). Resiliensi Pada Remaja Yang Mengalami Broken Home. Jurnal Psikologi.

Santrock Jhon. W. Dalam Amrullah (2013). Remaja. Edisi Kesebelas Jakarta: Erlangga.

Yuniana. (2012). Kesejahteraan Subjektif Pada Yatim Piatu (Mustadh'afin). Skripsi (tidak diterbitkan). Fakultas Psikologi Universitas Ahmad Dahlan Yogyakarta. 